\title{
Probiotics and animal feed in primates feeding
}

\author{
N.V. Gaponov ${ }^{1,2, *}$, O.P Neverova ${ }^{3}$, O.V. Gorelik ${ }^{3}$, and A.V. Stepanov ${ }^{3}$ \\ ${ }^{1}$ FSBI Scientific «Research Institute of Medical Primatology», World st., 177, 354376 Krasnodar \\ Territory, Sochi, Russia \\ ${ }^{2}$ All-Russian Lupine Scientific Research Institute - Branch of the FSBS Institution «Federal Williams \\ Research Center of Forage Production and Agroecology», 241524 Bryansk region, p/o Michurinskiy, \\ Berezovaya str., 2, Russia \\ ${ }^{3}$ Ural State Agrarian University, 620075 Yekaterinburg, Russia
}

\begin{abstract}
This paper presents the results of experiments on primates feeding. In diet structures that were used animal feed, of which fish flour is the most valuable, as found, for monkeys, due to its unique chemical composition. And the effect of the probiotic complex "Bactistatin" on the digestibility of feed in the diet of rhesus monkeys was studied. This preparation belongs to the new generation of probiotics. It is a biological product with immobilized probiotic strains and their metabolites. The study was conducted on a large population of male rhesus macaques in enclosure conditions. Feeding diets, their nutritional value as a result of the inclusion of fish flour in the amount of $18 \%$ were studied. And also, the effect of "Bactistatin" in the amount of $3 \mathrm{~g} / \mathrm{h}$ ead, on the formation of symbiotic microflora of the gastrointestinal tract, was studied in order to improve the absorption of nutrients in complete feed. Changes in homeostasis during the experiment were controlled by hematological and biochemical parameters of the blood of both experimental and control primates. At the end of the experiment, the cost of feed, nutrients, and exchange energy per head was calculated. The experimental data obtained were analyzed and mathematically processed.
\end{abstract}

\section{Introduction}

At present, the market for microecological agents and probiotic feeds for therapeutic and prophylactic purposes is approaching US \$ 30 billion and has an annual growth rate of about $3-5 \%[9 ; 16]$. The effectiveness of probiotics is determined by their adaptive and probiotic potentials $[11 ; 14]$. The adaptive potential includes the resistance of probiotic bacteria to physical and chemical stresses (acidic ${ }_{\mathrm{p}} \mathrm{H}$, oxidative and osmotic stresses), the severity of adaptive metabolism (the ability to utilize carbohydrate and other substrates), as well as the ability to adhere and its severity (the number and types of surface mucin- and fibronectin binding proteins, exopolysaccharides, lipoteichoic acid, etc.). Probiotic potential of probiotics is associated with the production of the underlying living organisms of many

\footnotetext{
* Corresponding author: nv.1000@bk.ru
} 
low molecular weight compounds of different chemical nature (autoinductor, chemokines, moduline, effectors, substrates, cosubstrates, enzymes, co-factors, metabolites, signaling molecules), similar to those of endogenous and food origin, as well as microbial compounds that eliminate (or suppress) the development of pathogenic and opportunistic microbes in the gastrointestinal tract using these drugs or positively affecting its autochthonous microbiota and intestinal epithelium, improving local and systemic immunity, activating metabolic and other processes localized or proceeding in the gastrointestinal tract. Attempts have been made to create symbiotic probiotics based on strains that simultaneously participate in the implementation of several physiological functions, biochemical or behavioral reactions; attempts were made to introduce nanoparticles containing certain lowmolecular compounds or their groups in the composition of probiotics and symbiotics. Probiotics are differentiated for a wide range of uses, for specific populations, including autoprobiotics for personal use. Probiotics based on genetically engineered strains that artificially introduce genetic determinants responsible for the synthesis of bacteriocins, antimicrobial enzymes, immunoglobulins, interferons, and other compounds that enhance the adaptive and probiotic potential of probiotic microorganisms have been developed $[13 ; 15]$.

Scientists refer to new-generation probiotics as biologics with immobilized probiotic strains and their metabolites, as well as synthetic compositions of autostimulants $[2 ; 9 ; 14]$. Such preparations include bactistatin. This preparation allows to form a microbiota in the gastrointestinal tract, which in turn, as part of a complex symbiotic system of the body, allows to favorably affect the digestive processes. But, in addition to the symbiotic mycobiota, a full-fledged balanced feeding is important. One of the main conditions for which is complete feed, which includes animal feed.

Animal feed is the most valuable source of protein for animals. The protein of most of them is rich in lysine and other essential amino acids and has a high biological value and digestibility. They contain a lot of B vitamins, including vitamin B12, which is not found in plant feed. Some of them are also a good source of fat-soluble vitamins. Animal feed is free of fiber and other carbohydrates, with the exception of milk, which contains the sugar lactose. Many of them are rich in calcium, phosphorus, magnesium, and iodine. These feeds are mainly used for monogastric and young animals of different species. Their main purpose is to supplement feed and mixed feeds with protein and amino acids, as well as B vitamins. Among animal feeds, the most important is fish flour, which has a specific special structure. First of all, we are talking about a surprisingly wide range of natural substances and minerals contained in fish flour: this is phosphorus (almost all seafood is rich in them), calcium, a whole set of amino acids, iodine, selenium, as well as vitamins A, D and B group. Each of these elements has its own useful properties, thanks to which the digestive processes are improved and the immune system is strengthened. Animals that receive fish flour are less susceptible to diseases, and due to the optimal ratio of amino acids in the composition of fish flour, young animals develop faster $[12 ; 6]$.

The aim of our research was to develop new feeding diets for rhesus macaques using fish flour and to study the effect of bactistatin in feeding diets on feed and nutrient costs.

\section{Research methods}

Experimental work was performed on male primates of the rhesus macaque species (macaca mulatta). For this purpose, 3 groups were formed, using the method of pairs of analogues by origin, physiological state, with an average age of 10 years, 12 heads in each group. The experiment was carried out in an open-air cage. The experiment was conducted in accordance with generally accepted research methods. The duration of the stated experi- 
ments was 92 days. [1; 7].

During the experiments, primate feeding was carried out with complete compound feeds, the nutritional value of which was developed according to the feeding standards of these primate species. The lack of certain types of amino acids, such as lysine and macronutrients in complete feed was restored by additives containing them. And the limit of methionine, for example, in feed is restored by adding its synthetic form, in the amount required to the norm $[8 ; 10]$. The scheme of this experiment is presented in table 1.

Table 1. Scheme of experiments on macaca mulatta

\begin{tabular}{|c|c|l|}
\hline Groups & $\begin{array}{c}\text { Number } \\
\text { of primates }\end{array}$ & \multicolumn{1}{|c|}{ Feeding conditions } \\
\hline $\begin{array}{c}\text { I } \\
\text { Control }\end{array}$ & 12 & Complete feed (CF) \\
\hline $\begin{array}{c}\text { II } \\
\text { Experiment }\end{array}$ & 12 & CF + "Bactistatin" 3 g/head. \\
\hline $\begin{array}{c}\text { III } \\
\text { Experiment }\end{array}$ & 12 & $\begin{array}{l}\text { From CF the following was replaced: egg powder - by } 70 \%, \\
\text { corn gluten - by } 2 \%, \text { sunflower flour y } 10 \%, \text { milk powder - by } \\
100 \%, \text { fish flour }-18.26 \%\end{array}$ \\
\hline
\end{tabular}

CF* - complete feed

Animal experiments were performed in accordance with the requirements of the guidelines for the maintenance of laboratory animals [18], the Helsinki Declaration (2000) and the EU Directive 2010/63/EU. The study was approved by the Bioethical Commission of the FSBSI "SRI MP".

The results were processed statistically and expressed as arithmetic averages and their standard errors. The statistical significance of the differences was determined using a single-factor analysis of variance with subsequent a posteriori adjustments for multiple comparisons using the Tukey and Sidak method. The accepted level of statistical significance is $\mathrm{p}<0.05$.

Primates in the control group consumed a complete balanced feed of own production of the FSBSI "SRI MP".

The 2nd experimental group received the probiotic complex bactistatin in the recommended ratio of $3 \mathrm{~g} /$ head per day in addition to the complete compound feed.

Test rhesus monkeys of the 3rd experimental group, the following components were replaced with fish flour in the nutritional formula: sunflower flour by $10 \%$, egg powder by $70 \%$, corn gluten by $2 \%$, dry milk by $100 \%$, as a result, fish flour in the diet structure was in the amount of $18 \%$.

Changes in the homeostasis and health status of primates resulting from the inclusion of fish flour and "Bactistatin" were monitored based on the results of hematological tests. For this purpose blood sampling in male rhesus macaques was carried out at the beginning of the experiment and at its end $[3 ; 4 ; 17 ; 18]$.

\section{Results and their discussion}

For the preparation of diets, the norms of primate nutritional requirements were taken, based on an in-depth analysis of literature data, scientific research, and achievements in the practical production of complete feed. According to the recommendations, the feeding period is divided into two-phase feeding (table 2). 
Table 2. Nutritional value of complete compound feeds

\begin{tabular}{|c|c|c|c|}
\hline Indicators & Complete feed, $C F$ & $\begin{array}{c}\mathrm{CF} \\
\text { with bactistatin }\end{array}$ & $\begin{array}{c}\text { CF } \\
\text { with fish flour }\end{array}$ \\
\hline EFU, primates & 1.33 & 1.33 & 1.33 \\
\hline EE, primates MJ & 13.36 & 13.36 & 13.30 \\
\hline Dry matter, $\mathrm{g}$ & 817.74 & 817.74 & 859.93 \\
\hline Crude protein, $g$ & 268.26 & 268.26 & 332.43 \\
\hline PP monkeys, $g$ & 226.51 & 226.51 & 297.15 \\
\hline Lysine, $g$ & 88.48 & 88.48 & 93.86 \\
\hline $\begin{array}{l}\text { Methionin+cysteine } \\
, \mathrm{g}\end{array}$ & 6.78 & 6.78 & 10.37 \\
\hline Tryptophan, g & 3.20 & 3.20 & 4.10 \\
\hline Raw fat, $g$ & 69.80 & 69.80 & 41.61 \\
\hline Raw fiber, $g$ & 39.30 & 39.30 & 37.30 \\
\hline NFES, including, $g$ & 283.60 & 283.60 & 253.52 \\
\hline Starch, g & 242.00 & 242.00 & 240.41 \\
\hline Sugar, g & 191.70 & 191.70 & 190.20 \\
\hline Calcium, $\mathrm{g}$ & 16.33 & 16.33 & 27.45 \\
\hline Phosphorus, g & 8.75 & 8.75 & 14.21 \\
\hline Magnesium, $g$ & 2.63 & 2.63 & 3.29 \\
\hline Potassium, $\mathrm{g}$ & 5.88 & 5.88 & 7.71 \\
\hline Sulfur, $g$ & 2.35 & 2.35 & 2.91 \\
\hline Iron, $\mathrm{mg}$ & $\overline{75.04}$ & 75.04 & 88.14 \\
\hline Copper, mg & 14.50 & 14.50 & 16.76 \\
\hline Zinc, $\mathrm{mg}$ & 20.87 & 20.87 & 37.53 \\
\hline Manganese, $\mathrm{mg}$ & 20.07 & 20.07 & 23.50 \\
\hline Cobalt, $\mathrm{mg}$ & 10.45 & 10.45 & 10.40 \\
\hline Iodine, $\mathrm{mg}$ & 0.18 & 0.18 & 0.61 \\
\hline Carotene, $\mathrm{mg}$ & 1.32 & 1.32 & 0.64 \\
\hline Vitamin A, MU & 800.21 & 800.21 & 0.21 \\
\hline Vitamin D, MU & 14.88 & 14.88 & 15.79 \\
\hline Vitamin E, mg & 6.12 & 6.12 & 8.60 \\
\hline Vitamin B12, mcg & 14.29 & 14.29 & 58.46 \\
\hline
\end{tabular}

The rations were equalized in terms of total nutrition, minerals, protein, and fat; the amino acid composition of the feed was taken into account to balance the rations for essential amino acids (lysine, methionine).

Primates of the I-th control group were fed with complete compound feed of own production of the FSBSI "SRI MP". In the composition, which accounted for $21.4 \%$ of wheat, soybean cake and sunflower - $17.42 \%$ and $13.83 \%$, respectively. Skimmed milk powder accounted for $14.39 \%$. In terms of energy, the complete feed was balanced by the inclusion of sunflower oil in its composition in an amount of $0.8 \%$. The remaining $32.16 \%$ of energy came from corn gluten, egg powder, and sugar, respectively $-11.24 \%, 13.35 \%, 3.3 \%$, and $4.27 \%$. Macro and microelements were balanced by the inclusion of premix in the recipe.

The recipe of the II experimental group was similar in the structure of ingredients to the I control group. But in addition to complete compound feeds, primates of the second experimental group received "Bactistatin", at the rate of $3 \mathrm{~g} / \mathrm{kg}$ of body weight.

Fish flour in the amount of $18 \%$ was added to the formula of complete compound feed of the III experimental group as animal feed. As a result, the recipe structure reduced the content of egg powder by $70 \%$, sunflower flour by $10 \%$, skimmed milk powder by $100 \%$, and corn gluten by $2 \%$.

Constancy of physical and chemical properties and chemical and morphological composition of blood is possible only in healthy primates. Based on this, the study of hematological parameters is important for the diagnosis of homeostasis. Table 3 
In the blood serum, its biochemical parameters were studied. In particular, total protein, glucose, bilirubin, phosphorus, and calcium[5].

Table 3. Blood biochemical parameters of primates $(\mathrm{X} \pm \mathrm{Sx})$

\begin{tabular}{|c|c|c|c|c|c|}
\hline Groups & $\begin{array}{r}\text { Glucose } \\
(\mathrm{mmol} / \mathrm{l})\end{array}$ & $\begin{array}{c}\text { Bilirubin } \\
\mathrm{mcmol} / \mathrm{l}\end{array}$ & $\begin{array}{c}\text { Phosphorus } \\
(\mathrm{mmol} / \mathrm{l})\end{array}$ & $\begin{array}{c}\text { Calcium } \\
(\mathrm{mmol} / \mathrm{l})\end{array}$ & $\begin{array}{c}\text { Protein } \\
(\mathrm{g} / \mathrm{l})\end{array}$ \\
\hline \multicolumn{7}{|c|}{ Beginning of the experiment } \\
\hline I-control & $3.73 \pm 0.30$ & $3.05 \pm 0.44$ & $1.12 \pm 0.16$ & $2.95 \pm 0.17$ & $91.65 \pm 4.01$ \\
\hline II-experiment & $4.76 \pm 0.56$ & $4.41 \pm 0.54$ & $1.24 \pm 0.10$ & $2.75 \pm 0.05$ & $87.29 \pm 2.50$ \\
\hline III-experiment & $3.20 \pm 0.34$ & $4.82 \pm 0.64$ & $1.48 \pm 0.18$ & $2.72 \pm 0.12$ & $87.96 \pm 5.9$ \\
\hline \multicolumn{7}{|c|}{ End of the experiment } \\
\hline I-control & $6.35 \pm 0.35$ & $11.66 \pm 3.1$ & $0.59 \pm 0.07$ & $2.91 \pm 0.08$ & $91.89 \pm 6.64$ \\
\hline II-experiment & $6.40 \pm 0.34$ & $17.61 \pm 4.83$ & $1.12 \pm 0.09^{*}$ & $2.88 \pm 0.13$ & $73.46 \pm 5.30$ \\
\hline III-experiment & $6.15 \pm 0.16$ & $6.15 \pm 1.40$ & $1.20 \pm 0.13$ & $3.24 \pm 0.03 *$ & $78.53 \pm 3.60$ \\
\hline
\end{tabular}

$\mathrm{p}<0.05^{*}$

In the diagnosis of internal non-infectious diseases, intoxications, blood biochemical parameters are of great value, but mainly reflect the metabolic processes and the level of feeding. As a rule,biochemical blood parameters do not fully provide answers to all the diagnosed questions, but with the correct understanding of physiological changes, they become a solid basis for making decisions for the development of scientifically based feeding standards.

The blood glucose level was determined to monitor the state of carbohydrate metabolism. The normal glucose level is (3.3-6.5 mmol/l). Hyperglycemia (increased blood sugar) is usually associated with feeding of large amounts of sugary feed, but in this case we can talk about better absorption of sugars from the diet.

Bilirubin increases during the violation of the liver functioning. Normal level - $(3,4-17,6$ $\mathrm{mmol} / \mathrm{l}$ ). In our experiment, the level of pigment, both at the beginning of the experiment and at the end of the experimental period, was within the physiological norm.

Phosphorus is a structurally necessary element for the functioning of nerve endings in muscle tissues. The norm for an adult healthy body is $(0.87-1.5 \mathrm{mmol} / \mathrm{l})$. The level of phosphorus in the blood of all experimental groups was lower than the background values, but was within the reference values.

The normal calcium level of adult primates is in the range $(2.25-3.0 \mathrm{mmol} / \mathrm{l})$. In our experiment, the calcium level was within the normal range.

Total protein, as the basis of the entire protein part of the blood, helps to determine the metabolic disorders and nutritional content of the diet, as well as the development of malignant neoplasms in the body. Increased protein is a sign of the development of tumors and rheumatic diseases, reduced protein - problems in the digestive organs. In adult primates, the protein norm is 64-93 g/l. Analysis of protein metabolism showed that the indicators of 
total protein are within the limits of physiological norms. This indicates a sufficient balance of protein diets.

The results of hematological studies convincingly showed that the biochemical parameters and complete blood analysis, after using fish flour and "Bactistatin" as part of the recipes by the end of the experiment, approached the reference values; this proves their positive effect on homeostasis, growth and development of male rhesus macaques.

The study of feed consumption indicators, when determining the effectiveness of the use of "Bactistatin" and fish flour, is necessary. Since feed makes up a significant amount in the structure of keeping primates cost, more than $75 \%$. Indicators of feed costs, most pronounced when testing experiments on a larger livestock, with open-air cage conditions table 4.

Based on the indicators of body weight, it can be seen that macaca mulatta males in the experimental groups were superior to their counterparts in the I-th control group.

The total increase over the experiment was the highest in primates of the III experimental group, and it was $890 \mathrm{~g}$. This is $261 \%$ higher than in the control group. This trend is also observed in the second experimental group, where the increase for the experiment was 620 and was higher by $182 \%$, respectively, with a high degree of confidence $(p<0.001)$.

Table 4. Feed costs per 1 head for the experiment

\begin{tabular}{|c|c|c|c|}
\hline \multirow{2}{*}{ Indicators } & \multicolumn{3}{|c|}{ Groups } \\
\cline { 2 - 4 } & Control & 2 Experiment & 3 Experiment \\
\hline Body weight, kg: & & & \\
\hline at the beginning of the experiment & $11.61 \pm 0.55$ & $9.30 \pm 0.36$ & $8.36 \pm 0.45$ \\
\hline at the end of the experiment & $11.95 \pm 0.50$ & $9.92 \pm 0.49$ & $9.25 \pm 0.40$ \\
\hline Increase for the experiment, $\mathrm{kg}$ & $0.34 \pm 0.33$ & $0.62 \pm 0.19^{* *}$ & $0.89 \pm 0.25^{*}$ \\
\hline$\%$ to control & 100 & 182 & 261 \\
\hline & & & \\
\hline Costs per 1 head & & & \\
\hline MJ & 3724.0 & 2070.5 & -61.48 \\
\hline \% to control & 100 & -44.40 & \\
\hline & & & 35.92 \\
\hline Crude protein, kg & 75.04 & & -52.13 \\
\hline
\end{tabular}

$\mathrm{p}<0.05^{*}, \mathrm{p}<0.001^{* *}$

The data in Table 4 indicate that the use of "Bactistatin" and fish flour in the diets contributed to the effective use of complete feed by experimental primates. Male rhesus macaques of all groups spent the same amount of food and nutrients per head per day, but for the resulting weight gain over the experiment, the costs were lower in the experimental groups. Bactistatin and fish flour had a positive effect on the costs of metabolic energy and crude protein. Significantly low feed costs are observed in the third experimental group. 
Here energy consumption was lower by $61.48 \%$, crude protein - by $52.13 \%$. In the II experimental group, the expenditure of exchange energy and raw protein was lower by $44.40 \%$ and $42.33 \%$, respectively.

Thus, the inclusion of fish flour and bactistatin in the diet structure of male rhesus macaques increases the weight gain by $261 \%$ and $182 \%$, respectively. At the same time, it helps to reduce the cost of nutrients and feed per 1 head.

\section{Conclusions}

According to the data obtained in the experiment, it can be argued that the introduction of fish flour into the composition of the complete recipes of the experimental groups of male rhesus monkeys had a positive effect on their nutritional value and the degree of assimilation of nutrients, which is reflected in the consumption of feed and metabolic energy per 1 head. This helps reduce feed costs and increases the profitability of monkeys keeping.

The use of the probiotic preparation "Bactistatin" allowed to normalize the symbiotic microflora of the digestive tract, and strengthen the natural resistance of the body of experimental monkeys, which provided better absorption of nutrients in the diet. This, in turn, is confirmed by the hematological indicators obtained as a result of the experiment and indicate a good state of health of rhesus macaques and the usefulness of the structure of recipes for complete compound feeds.

\section{References}

1. P.I. Viktorov, V.K. Menkin, B43 Methods and organization of zootechnical experiments (M.: Agropromizdat, 1991)

2. N.V. Gaponov, Vestnik of the KrasSAU, 7(148), 96-102 (2019)

3. N.V.Gaponov, Yu.P. Chuguev, I.I. Chugueva, Topical issues of Medicine, 6, 16-22 (2019)

4. N.V. Gaponov, Yu.P. Chuguev, I.I. Chugueva, Veterinary science, 1, 43-47 (2020)

5. N.V. Gaponov, S.V. Svistunov, Collection of scientific papers of the Krasnodar Scientific Ccenter for Animal Science and Veterinary Medicine, 8(1), 188-193 (2019)

6. N.V. Gaponov, G.L.Yagovenko, Feed Production, 2, 43-46 (2020)

7. A.P. Kalashnikov [et al.], Norms and rations of feeding of agricultural animals (Moscow, 2003)

8. A.I. Ovsyannikov, Fundamentals of experimental business in animal husbandry (Moscow: Kolos, 1967)

9. B.A. Shenderov, Metamorphoses, 5, 72 - 80 (2014)

10. N.V. Gaponov, S.V. Svistunov, N.N. Bondarenko, I.A. Romanenko, Bulletin the National academy of sciences of the Republic of Kazakhstan, 2(384), 22 - 28 (2020)

11. S. Lebeer, J. Vanderleyden, S.C.J. de Keersmaeker, Microbiol Mol Biol Rev., 72, 728764 (2008)

12. R.D. Miles, F.A. Chapman, The benefits of fish Meal in Aquaculture diets. University of Florida (USA,2006) URL: http:// www.thefishsite.com/articles/200/the-benefits-offish-meal-in-aquaculture-diets

13. M. Mimee, R.J. Citorik, T.K. Lu, Adv Drug Deliv Rev, 105, 44-54, 2006

14. B.A. Shenderov, Probiotics and Functional Foods, Food Engineering, Encyclopedia of 
Life Support Systems (EOLSS) (Developed under the Auspices of the UNESCO, Eolss Publishers, Oxford, UK., 2011)

15. J.L. Sonnenbur, F. Backhed, Nature, 535, 56- 64 (2016)

16. K. Venema, A.P. do Carmo, Probiotic and Prebiotics: Current Research and Future Trends (Wageningen: Caister Academic Presss, 2015)

17. N.V. Gaponov, G.L. Yagovenko, E3S Web of Conferences, 176, 01002 (2020)

18. N.V. Gaponov, O.P. Neverova, O.V. Gorelik, S.Y. Kharlap, T.I. Bezhinar, E3S Web of Conferences, 176, 01004, (2020) 